\title{
Plateletcrit as a Determinant of Diffusion-Restricted Lesion Volume in Diffusion-Weighted Imaging
}

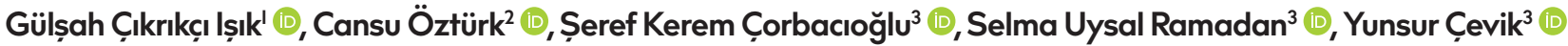 \\ 'Department of Emergency Medicine, University of Health Sciences Kecioren Training and Research Hospital, Ankara, Turkey \\ ${ }^{2}$ Department of Radiology, Kecioren Training and Research Hospital, Ankara, Turkey \\ ${ }^{3}$ Department of Emergency Medicine, Kecioren Training and Research Hospital, Ankara, Turkey
}

ORCID iDs of the authors: G.C̣.I. 0000-0002-6067-705I; C.0̈. 0000-0003-3659-5I84; Ș.K.C̣. 0000-000I-7802-8087; S.U.R. 0000-00023653-7892; Y.C.. 0000-0003-1325-0909.

\section{Cite this article as: Çıkrıkc̣ı Ișık G, Öztürk C, Çorbacıoğlu ȘK, Uysal Ramadan S, C̣evik Y. Plateletcrit as a Determinant of Diffusion-} Restricted Lesion Volume in Diffusion-Weighted Imaging. Cyprus J Med Sci 202I; 6(I): 50-3.

\section{BACKGROUND/AIMS}

Platelet indices have predictive and prognostic roles in ischemic events. This study aimed to evaluate the correlation between plateletcrit (PCT), one of the platelet indices that provide more comprehensive data about total platelet mass, and diffusion-restricted lesion volume by diffusion-weighted magnetic resonance imaging (DW-MRI).

\section{MATERIAL and METHODS}

All the patients admitted to the emergency department between September 2018 and September 2019 were retrospectively analyzed Patients who underwent both DW-MRI and complete blood count for any reason were included. All DW-MRI results were interpreted again, and restricted lesion volumes were calculated by a radiologist. Lesions $>4 \mathrm{~cm} 3$ in volume were considered as large restrictions. Statistical analysis was performed using IBM Statistical Package for the Social Sciences Statistics for windows, version 22.0.

\section{RESULTS}

A total of 505 patients were included, of whom 285 (56.4\%) had no diffusion-restricted lesions on DW-MRI. Platelet indices were compared between the patients with diffusion restriction and those without restriction on DW-MRI. In-group comparisons of these parameters between small and large restrictions were also conducted. There were no significant differences between the groups in terms of age, gender, and platelet indices. Correlations of stroke volume and platelet indices were also analyzed, and we found no correlations between these parameters ( $P>.05$ for all).

\section{CONCLUSION}

This study showed us that neither plateletcrit nor other platelet indices were predictors of diffusion restricted lesion volume in diffusion-weighted imaging.

Keywords: Diffusion magnetic resonance imaging, blood platelets, mean platelet volume, platelet count

\section{INTRODUCTION}

Stroke, with a prevalence of $2.6 \%$ in individuals aged $>20$ years, is an important cause of death around the world.' Approximately $85 \%$ of strokes are ischemic in origin, and it is well documented that there is a direct relationship between ischemic stroke and platelet indices, stemming from the role of platelet activation in the process of atherosclerosis $(\mathrm{I}, 2)$.

Platelet indices such as mean platelet volume (MPV), platelet count (PC), and platelet distribution width (PDW) are part of a routine complete blood count(3). It has been shown that platelets with larger volumes are more active enzymatically and metabolically and thus have higher thrombotic ability $(4,5)$. Plateletcrit $(P C T)$, another platelet index, has the great advantage of providing more comprehensive data about total platelet mass because it is equivalent to MPV and PC (PCT $=P C \times M P V / 10)(3,6,7)$.

Diffusion-weighted magnetic resonance imaging (DW-MRI) is the hallmark imaging approach for acute cerebral infarction, especially in emergency departments, because of the restricted diffusion usually developing within I hour of insult(7). 
Although this imaging abnormality is less frequently seen with neoplasms, intracranial infections, and demyelinating processes, the vast majority of restricted-diffusion abnormalities on MRI result from acute stroke (7). It is also known that early ischemic lesion volume on DW-MRI is an independent predictor of stroke outcome(8).

Many existing studies have shown the predictive or prognostic roles of PCT in many different ischemic events, such as cerebrovascular accidents, coronary lesions, and even recurrent abortions (9-II). However, to the best of our knowledge, there is no study on PCT and its association with diffusion-restricted lesion volume on DW-MRI. This study aimed to evaluate the correlation between these 2 parameters to understand whether PCT might be a predictor of diffusion-restricted lesion volume on DW-MRI.

\section{MATERIAL and METHODS}

This study was conducted in a training and research hospital after obtaining the approval of the local ethics committee. All patients admitted to the emergency department between September 2018 and September 2019 were retrospectively analyzed. Patients who underwent both DW-MRI and a complete blood count for any reason were included in the study. Patients lacking either of these examinations, patients with hematological disorders affecting platelets, and patients with a history of acute trauma were excluded.

\section{Neuroimaging Protocol and Analysis}

Standard DW-MRI examinations of the subjects in the supine position were performed using a I.5-T clinical scanner (MAGNETOM Avanto, Siemens Healthineers, Erlangen, Germany). DW-MRI was performed with the following parameters: 8 slices, 4300/102 ms (repetition time/echo time), slice thickness of $5 \mathrm{~mm}$, gap of I mm, field of view of $22 \mathrm{~cm}$, and $b$ values of 0 and $1,000 \mathrm{~s} / \mathrm{mm}^{2}$. The lesion volumes were determined after the images were transferred to a workstation (syngo.via, Siemens Healthineers). An experienced reader (CÖ, a radiologist with 10 years of experience) blinded to the laboratory data reviewed all DW-MRI results to manually measure the ischemic lesion volumes by using the volume of interest ( $\mathrm{VOI}$ ). Ischemic areas observed in diffusion images were manually marked using VOI. Marking was performed on all sections where ischemic areas were observed, and then the ischemic volume was automatically calculated by the device. In cases with more than one ischemic focus, the measurement of each ischemic area was done separately, and the total volume of ischemic areas was calculated. Lesions greater than $4 \mathrm{~cm}^{3}$ were considered as large restrictions; this threshold was determined according to a study of Mohamed et al. (2).

\section{Main Points:}

- To the best of our knowledge this is the first study investigating the relationship between platelet indices and lesion volume on diffusion-weighted magnetic resonance imaging (DW-MRI)

- Plateletcrit was not a predictor of diffusion-restricted lesion volume on DW-MRI

- There was also no correlation between the other platelet indices (platelet count, mean platelet volume, and platelet distribution width) and diffusion-restricted volumes.

\section{Measurement of Platelet Indices}

In general practice, the blood of a patient is sampled immediately after admission to the emergency department and before the administration of medications and intravenous fluids. Samples were collected in ethylenediaminetetraacetic acid tubes and were processed in the laboratory of the emergency department within 2 hours using a Mindray BC-6800 hematology analyzer (Mindray). The normal ranges of platelet indices in our laboratory are as follows: PC, 156-373 × 1033 $/ \mu \mathrm{L}$; MPV, 6.9-10.8 fL; PDW, 12-25; and PCT, 0\%-10\%.

\section{Statistical Evaluation}

Statistical analysis was performed using IBM Statistical Package for the Social Sciences Statistics for windows, version 22.0 (IBM SPSS Corp.; Armonk, NY, USA). Categorical variables are provided as frequency and percentage. Continuous variables are given as median and interquartile range (IQR). The Shapiro-Wilk test was used to determine normality. The Mann-Whitney $U$ test was used for two-group comparisons of continuous variables. Pearson chi-square tests were used to compare categorical variables. The Spearman correlation test was used for correlation analyses. Values of $P<.05$ were considered statistically significant.

\section{RESULTS}

A total of 505 patients, including 291 women (57.6\%) and 214 men (42.4\%) with a median age of 73 (IQR: 64-8I) years, were included in this study. The most common complaints during the emergency department admission were general disturbances (25.1\%), motor deficiencies (17.4\%), dysarthria (13.3\%), and vertigo (II.3\%). There were no diffusion-restricted lesions on DW-MRI for 285 patients $(56.4 \%)$. In the other patients, diffusion restrictions were most commonly seen as cortical $(n=66)$, focal $(n=40)$, and diffuse subcortical $(n=39)$ restrictions. The outcomes of the patients were also analyzed; 257 (50.7\%) were discharged, 5 I (I0.1\%) were transferred to a stroke center, and 94 (18.6\%) were admitted to the intensive care unit (Table I).

Platelet indices were compared between the groups of patients with and without diffusion restriction on DW-MRI. In-group comparisons of these parameters between patients with small (Group 2a; patients with restrictions $<4 \mathrm{~cm}^{3}$ ) and large (Group $2 \mathrm{~b}$; patients with restrictions $\geq 4 \mathrm{~cm}^{3}$ ) restrictions were conducted. There were no significant differences between the groups in terms of age, sex, and platelet indices ( $p>05$ for all) (Table 2).

The correlations of diffusion-restricted lesion volume and platelet indices were also analyzed. We found no correlation between these parameters ( $p>05$ for all). There was no correlation between platelet indices and stroke volume even when the analysis was repeated while including only cortical restrictions (Table 3).

\section{DISCUSSION}

Our results showed that PCT was not a predictor of diffusion-restricted lesion volume on DW-MRI. As in PCT, there was also no correlation between the other platelet indices (PC, MPV, and PDW) and diffusion-restricted volumes.

Platelet indices, given automatically by most cell counters, have been used in clinical practice only for the differential diagnosis 
TABLE I. General characteristics of the patients

\begin{tabular}{|c|c|c|}
\hline Characteristic & Number & Percent (\%) \\
\hline Age, years & 73 (IQR: 64-8I) & \\
\hline \multicolumn{3}{|l|}{ Gender } \\
\hline Female & 291 & 57.6 \\
\hline Male & 214 & 42.4 \\
\hline \multicolumn{3}{|l|}{ Complaint at admission } \\
\hline General disturbance & 127 & 25.1 \\
\hline Motor deficiencies & 88 & 17.4 \\
\hline Dysarthria & 67 & 13.3 \\
\hline Vertigo & 57 & 11.3 \\
\hline Sensorial deficiencies & 37 & 7.3 \\
\hline Syncope & 29 & 5.7 \\
\hline Seizure & 19 & 3.8 \\
\hline Others & 81 & 16 \\
\hline \multicolumn{3}{|l|}{ Diffusion-restricted lesion on DW-MRI } \\
\hline None & 285 & 56.4 \\
\hline Cortical & 66 & |3.| \\
\hline Focal & 40 & 7.9 \\
\hline Diffuse subcortical & 39 & 7.7 \\
\hline Subcortical & 35 & 6.9 \\
\hline Lacunar & 28 & 5.5 \\
\hline Mass lesion & 5 & 1 \\
\hline Lacunar + diffuse subcortical & 5 & 1 \\
\hline Lacunar + Subcortical infarct & 2 & 0.4 \\
\hline \multicolumn{3}{|l|}{ Outcome } \\
\hline Discharged & 256 & 50.7 \\
\hline Transmitted to a stroke center & 51 & I0.1 \\
\hline Admitted to an intensive care unit & 94 & 18.6 \\
\hline Admitted to the neurology department & 69 & 13.7 \\
\hline Admitted to other departments & 35 & 6.9 \\
\hline
\end{tabular}

of thrombocytopenic disorders. Recent studies did indicate that platelet indices and thrombotic events were strictly related, but the cause-and-effect relationship between them is still unclear (12). PCT, also known as platelet mass, is a platelet index calculated using PC and MPV and is accepted as an indicator of circulating platelets in a unit volume of blood $(2,3)$. It has been shown that high PCT values on admission are independently associated with long-term adverse outcomes in patients with acute coronary syndromes $(3,5)$. Akpınar et al. also showed that PCT might be a useful predictor of slow coronary flow phenomenon, a delayed opacification of distal vessels on coronary angiography in the absence of significant epicardial coronary stenosis (13).

Stroke is another clinical entity that results in changes in platelet indices whose role in the pathogenesis of atherothrombosis and inflammation has been already documented (14). Studies on the prediction value of PC and MPV for the outcome of stroke survivors have yielded inconsistent findings (I5). However, Mohammed et al. showed that PCT was significantly correlated with poor functional outcomes in cases of acute stroke (2).

Lesion volume is believed to be an important parameter reflecting the primary pathological condition, and the extent of this pathological condition is related to neurological deficits and functional outcomes (16). Vincent et al. showed that the DWMRI lesion volume measured within 48 hours of symptom onset was an independent risk factor for functional independence (8).

$\begin{array}{lcc}\text { TABLE 3. Correlation of platelet indices with stroke volume } & \begin{array}{c}\text { Correlation } \\ \text { with stroke } \\ \text { volume for all } \\ \text { restrictions }(\mathbf{n}=220) \\ \text { P-value }\end{array} & \begin{array}{c}\text { Correlation with } \\ \text { stroke volume for } \\ \text { only cortical } \\ \text { restrictions }(\mathbf{n}=66) \\ \text { P-value }\end{array} \\ \text { Platelet indices } & .895 & .64 \\ \text { PC } & .319 & .87 \\ \text { MPV } & .764 & .17 \\ \text { PDW } & .869 & .76 \\ \text { PCT } & \end{array}$

MPV, mean platelet volume; PC, platelet count; PCT, plateletcrit; PDW, platelet distribution width.

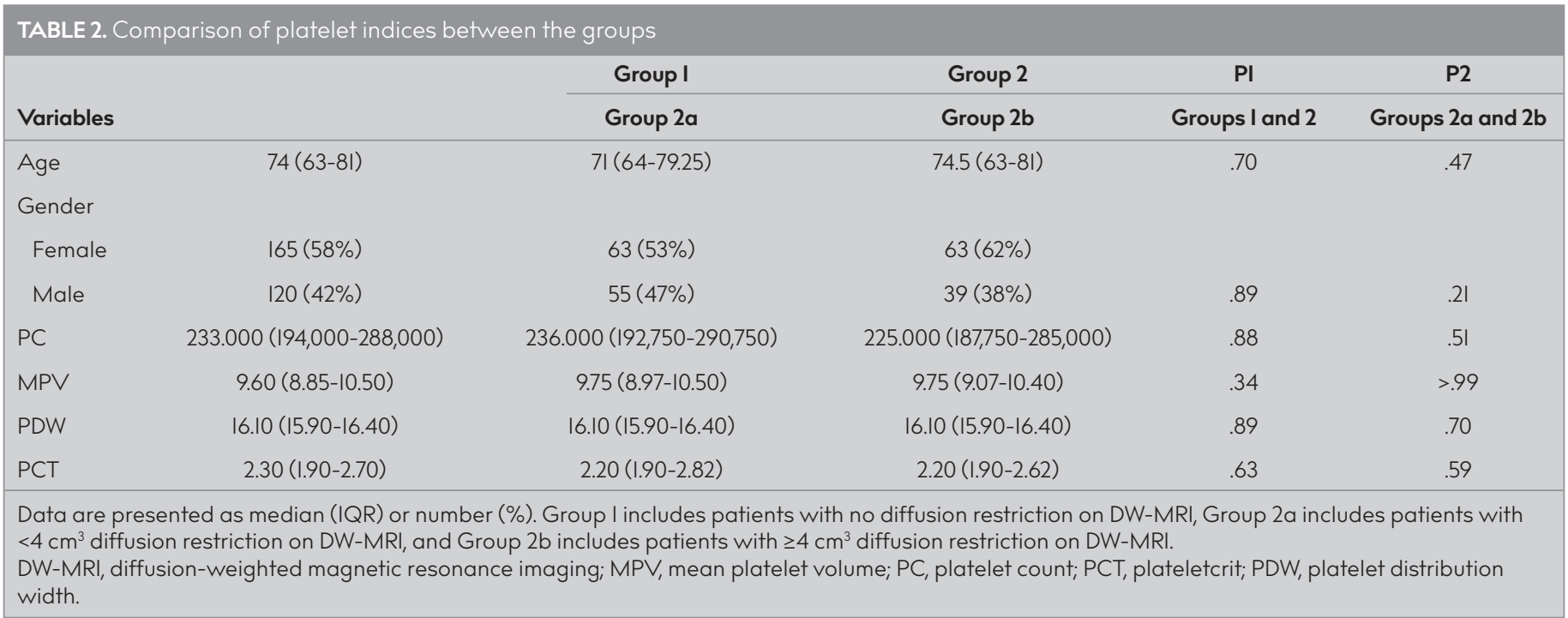


Different molecules, such as free fatty acids, vitamin D, and circulating endothelial microparticles have been investigated as determinants of ischemic lesion volume (17-19). However, no previous study investigating the relationship between platelet indices and lesion volume has been found in the literature.

DW-MRI is a preferred imaging modality in emergency settings because restriction usually develops within I hour of insult. The majority of restricted-diffusion abnormalities result from acute stroke, and the diagnosis may be difficult when this imaging feature results from different causes because many diseases, such as seizures, neoplasms, head injury, and even cyanide poisoning, hyperglycemia, or phenylketonuria can cause diffusion restriction (7). Therefore, all diffusion-restricted lesions were included in this study. To our knowledge, this is the first study investigating the relationship between platelet indices and diffusion-restricted lesion volume on DW-MRI.

This study has some limitations. First, because this was a retrospective study, we could not follow the patients and only evaluated the data during the emergency department process; therefore, we did not know the definitive diagnosis and outcomes of the patients. Second, platelet indices are affected by many clinical situations such as inflammation and comorbid diseases, and we did not exclude these confounding factors. However, because it would not have been possible to exclude those confounding factors in clinical practice, we planned the study considering that platelet indices should predict diffusion-restricted lesion volume in the presence of those confounding factors if they had a real predictive role.

In this study on the role of platelet indices in determining diffusion-restricted lesion volume on DW-MRI, no relationship was found between restricted lesion volume and the measured variables (PCT, PC, MPV, and PDW). To accurately determine the relationship of platelet indices with diffusion-restricted lesion volume and outcome in stroke survivors, further studies need to be conducted with larger sample sizes and patients with definitive diagnoses.

Ethics Committee Approval: Ethics committee approval was received for this study from the ethics committee of Keçiören Training and Research Hospital (Approval date: 27.II.2019, No: 2012-KAEK-15/1991).

Informed Consent: N/A

Peer-review: Externally peer-reviewed.

Author contributions: Concept - G.C.I.; Design - G.C.I.; Supervision - Y.C.; Resource - C.Ö., S.U.R.; Materials - Ș.K.C.., C.Ö.; Data Collection and/or Processing - G.C.I., C.Ö;; Analysis and/or Interpretation - G.C..I., Ș.K.C.; Literature Search - G.C..I., Y.C..; Writing - G.C..I; Critical Reviews - Ș.K.C.., Y.C., S.U.R.

Conflict of Interest: Authors have no conflicts of interest to declare.

Financial Disclosure: The authors declared that this study has received no financial support.

\section{REFERENCES}

I. Guzik A, Bushnell C. Stroke Epidemiology and Risk Factor Management. Continuum (Minneap Minn) 2017; 23 (I, Cerebrovascular Disease): 15-39. [Crossref]
2. Mohamed AB, Elnady HM, Alhewaig HK, Moslem Hefny H, Khodery A. The mean platelet volume and plateletcrit as predictors of shortterm outcome of acute ischemic stroke. Egypt J Neurol Psychiatr Neurosurg 2019; 55(I): 4. [Crossref]

3. Gul M, Uyarel H, Akgul O, Akkaya E, Surgit O, Cakmak HA, et al. Long-term prognostic significance of admission plateletcrit values in patients with non-ST elevation myocardial infarction. Blood Coagul Fibrinolysis 2016; 27(6): 696-70I. [Crossref]

4. Akpinar I, Sayin MR, Gursoy YC, Karabag T, Kucuk E, Buyukuysal $M C$, et al. A platelet marker associated with saphenous vein graft disease. Herz 2014; 39(I): 142-8. [Crossref]

5. Uğur M, Ayhan E, Bozbay M, Çiçek G, Ergelen M, Ișık T, et al. The independent association of plateletcrit with long-term outcomes in patıents undergoing prımary percutaneous coronary interventıon. J Crit Care 2014; 29(6): 978-8I. [Crossref]

6. Aslan S, Demir AR, Demir Y, Tașbulak Ö, Altunova M, Karakayalı M, et al. Usefulness of plateletcrit in the prediction of major adverse cardiac and cerebrovascular events in patients with carotid artery stenosis. Vascular 2019; 26: 1708538119847898. [Crossref]

7. Pasquale F. Finelli. Diagnostic approach to restricted-diffusion patterns on MR imaging. Neurol Clin Pract 2012; 2(4): 287-93. [Crossref]

8. Thijs VN, Lansberg MG, Beaulieu C, Marks MP, Moseley ME, Albers GW. Is early ischemic lesion volume on diffusion-weighted imaging an independent predictor of stroke outcome? A multivariable analysis. Stroke 2000; 3I(II): 2597-602. [Crossref]

9. Özkan B, Arik OZ, Gözükara MY, Șahin DY, Topal S, Uysal OK, et al. Mean platelet volume is related with ischemic stroke in patients with sinus rhythm. Blood Coagul Fibrinolysis 2016; 27(5): 490-3. [Crossref]

10. Cetin MS, Ozcan Cetin EH, Akdi A, Aras D, Topaloglu S, Temizhan A, et al. Platelet distribution width and plateletcrit: novel biomarkers of ST elevation myocardial infarction in young patients. Kardiol Pol 2017; 75(10): 1005-12. [Crossref]

II. Aynıglu O, Isık H, Sahbaz A, Harma MI, Isık M, Kokturk F. Can Plateletcrit be a Marker for Recurrent Pregnancy Loss? Clin Appl Thromb Hemost 2016; 22(5): 447-52. [Crossref]

12. Noris P, Melazzini F, Balduini CL. New Roles for Mean Platelet Volume Measurement in the Clinical Practice? Platelets 2016; 27(7): 607-12. [Crossref]

13. Akpinar I, Sayin MR, Gursoy YC, Aktop Z, Karabag T, Kucuk E, et al. Plateletcrit and Red Cell Distribution Width Are Independent Predictors of the Slow Coronary Flow Phenomenon. J Cardiol 2014; 63(2): I12-8. [Crossref]

14. Sadeghi F, Kovács S, Zsóri KS, Csiki Z, Bereczky Z, Shemirani AH. Platelet Count and Mean Volume in Acute Stroke: A Systematic Review and Meta-Analysis. Platelets 2020; 31(6): 731-9. [Crossref]

15. Farah R, Samra N. Mean Platelets Volume and Neutrophil to Lymphocyte Ratio as Predictors of Stroke. J Clin Lab Anal 2018; 32(I): e22189. [Crossref]

16. Schiemanck SK, Kwakkel G, Post MW, Prevo AJ. Predictive value of ischemic lesion volume assessed with magnetic resonance imaging for neurological deficits and functional outcome poststroke: A critical review of the literature. Neurorehabil Neural Repair 2006; 20(4): 492-502. [Crossref]

17. Chung JW, Seo WK, Kim GM, Chung CS, Lee KH, Bang OY. Free fatty acid as a determinant of ischemic lesion volume in nonarterial-origin embolic stroke. J Neurol Sci 2017; 382: II6-21. [Crossref]

18. Turetsky A, Goddeau RP Jr, Henninger N. Low Serum Vitamin D Is Independently Associated with Larger Lesion Volumes after Ischemic Stroke. J Stroke Cerebrovasc Dis 2015; 24(7): 1555-63. [Crossref]

19. Simak J, Gelderman MP, Yu H, Wright V, Baird AE. Circulating endothelial microparticles in acute ischemic stroke: a link to severity, lesion volume and outcome. J Thromb Haemost 2006; 4(6): 1296-302. [Crossref] 